FACULDADE DA AMAZONIA OCIDENTAL - FAAO CURSO DE DIREITO

\title{
Consumo Consciente
}

\author{
Rio Branco - Acre
}

2019 


\section{Título do Trabalho}

Trabalho apresentado no Curso de Direito instituição de ensino superior FAAO, como requisito para a realização da disciplina de: Direito Civil.

\section{RIO BRANCO -AC}






\section{RESUMO}

Este trabalho tem como objetivos qualificar o consumerismo, também chamado de consumo consciente, ou sustentável, identificar os principais fenômenos jurídicos decorrentes desta mudança nas relações de consumo e interpretar, a partir do Código de Defesa do Consumidor, a responsabilidade dos fornecedores no que tange ao incentivo ao consumo irrefletido de produtos potencialmente danosos à saúde e ao meio ambiente. Para atingir essas metas foi realizada a análise e interpretação do Código de Defesa do Consumidor e da Lei de Crimes Contra a Ordem Tributária, a partir da ótica do avanço agressivo do consumerismo na sociedade brasileira. Tal análise evidenciou que o direito do consumidor no Brasil é determinado como um valor constitucional, assentado no Art. $5^{\circ}$ da Constituição Federal. A mesma base fundamental do ordenamento jurídico defende todas as demais garantias atinentes aos direitos humanos, de modo que enquanto as relações de consumo se mantiverem em harmonia com as condições mínimas de dignidade humana não há contradição na lei, pois que estes fundamentos permanecem em estado de horizontalidade jurídica. Entretanto persistindo a redução no consumo, ocorre a desarmonização de tais ordenamentos, uma vez que o consumerismo promove a depressão das condições mínimas de estabilidade econômica, interferindo na capacidade do Estado de fomentar os direitos essenciais.

Palavras-chave: consumo consciente; relações de consumo; consumerismo; consumo sustentável; Código de Defesa do Consumidor 


\begin{abstract}
This paper aims to qualify consumerism, also known as conscious or sustainable consumption, identify the main legal phenomena arising from this change in consumer relations and interpret, from the Consumer Protection Code, the responsibility of suppliers with regard to encouraging the unreasonable consumption of products that are potentially harmful to health and the environment. To achieve these goals, the analysis and interpretation of the Consumer Protection Code and the Crimes Law against the Tax Order were conducted from the perspective of the aggressive advance of consumerism in Brazilian society. This analysis showed that the consumer's right in Brazil is determined as a constitutional value, based on Article 5 of the Federal Constitution. The same fundamental basis of the legal system defends all other guarantees regarding human rights, so that as long as consumer relations remain in harmony with the minimum conditions of human dignity, there is no contradiction in the law, since these grounds remain in a state of legal horizontality. However, as the reduction in consumption persists, the disharmonization of such orders occurs, since consumerism promotes the depression of the minimum conditions of economic stability, interfering with the state's capacity to promote essential rights.
\end{abstract}

Key words: conscious consumption; consumer relations; consumerism; sustainable consumption; Consumer Protection Code 


\section{SUMÁRIO}

\section{Sumário}

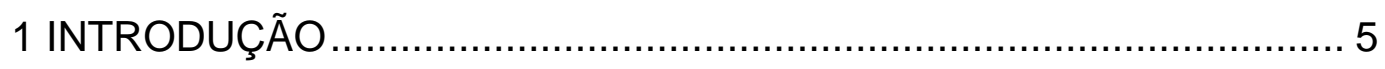

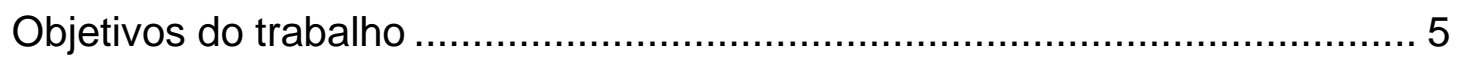

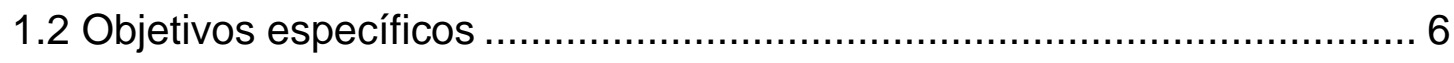

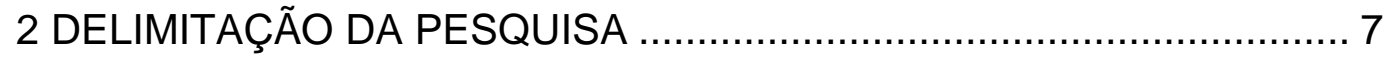

3 CÓDIGO DE DEFESA DO CONSUMIDOR E CONSUMERISMO......... 9

4 OS CRIMES CONTRA A ORDEM TRIBUTÁRIA E CONSUMERISMO

5 CONCLUSÃO 15

REFERÊNCIAS 17 


\section{INTRODUÇÃO}

A demanda social por consumo consciente tornou-se um poder orientador das relações comerciais, produzindo novas posturas morais frente ao mercado e desenvolvendo um tipo diferenciado de comportamento ético, o consumerismo. A difusão deste tipo de postura em uma população mais informada e ciente da sua responsabilidade para com a natureza, a sociedade e as gerações futuras exige o desenvolvimento congruente da interpretação da norma jurídica no que diz respeito às relações de consumo.

Grandes obras, como aeroportos, usinas e estações petrolíferas, por exemplo, foram projetados em perspectiva de crescimento sustentado da demanda por longos períodos de tempo. Supondo um horizonte de consistente decréscimo do consumo, que tipo de implicações recaem sobre os diversos atores sujeitos às frustrações de receitas e demais fenômenos econômicos e sociais decorrentes de tais mudanças?

Outra questão que surge é: em que termos pode ser considerado crime contra as relações de consumo, previsto no Art. $7^{\circ}$ da Lei de Crimes Contra a Ordem Tributária (Lei no 8.137/ 1990), o incentivo ao consumo irrefletido de produtos potencialmente danosos à saúde e ao meio ambiente?

Estas e outras questões pertinentes ao consumo consciente são tratadas nesta pesquisa a partir da leitura interpretativa do Código de Defesa do Consumidor (Lei no 8.078/ 1990) e de outras peças jurídicas, que se fazem necessárias para clarificar o entendimento sobre a legislação brasileira pertinente.

\section{Objetivos do trabalho}

Esta pesquisa se destina a evidenciar os principais efeitos jurídicos da redução do consumo, promovida pela conscientização ambiental massiva da 
população brasileira, a partir da leitura e interpretação do Código de Defesa do Consumidor.

\subsection{Objetivos específicos}

$\checkmark$ Qualificar o consumerismo;

$\checkmark$ Identificar os principais fenômenos jurídicos oriundos dessa mudança nas relações de consumo;

$\checkmark$ Interpretar, a partir do Código de Defesa do Consumidor, a responsabilidade dos fornecedores quanto ao incentivo ao consumo irrefletido de produtos potencialmente danosos à saúde e ao meio ambiente. 


\section{DELIMITAÇÃO DA PESQUISA}

Em análise sobre os danos morais decorrentes das relações de consumo, Antunes (2009, p. 179) propõe que, ao concretizar o direcionamento dado pela Constituição da República(CF) de 1988, o Código de Defesa do Consumidor foi orientado pela segurança e pela justiça que devem acompanhar o desenvolvimento social e da economia brasileira, prevendo a divisão de danos ocorridos nas relações de consumo.

Observa-se, em tal interpretação, uma perspectiva datada, que foi orientada por uma ânsia perpétua de crescimento e que considera apenas o viés econômico e social do progresso, sem refletir de forma sistemática sobre os impactos negativos de tal fenômeno.

A partir da década de 1990, com a grande publicidade lançada sobre os argumentos dos ambientalistas na Eco 92, as questões ambientais deixaram de ser periféricas no ordenamento jurídico e passaram a ocupar energias significativas dos legisladores e da sociedade, como na aprovação do Código Florestal Brasileiro (Lei o 12.651/ 2012), que demandou, décadas de debates, emendas e contratempos entre os poderes Legislativo e Executivo.

Com as inegáveis mudanças climáticas em curso e um conhecimento mais generalizado sobre os efeitos negativos das atividades antrópicas sobre o ambiente, surge uma nova perspectiva de desenvolvimento, definida originalmente em 1987 pelo Relatório Bruntldand (Our Common Future) como desenvolvimento sustentável, caracterizado como um tipo de progresso que garante o direito das gerações futuras de também se desenvolverem. A noção de sustentabilidade se difundiu para as áreas sociais, ambientais e econômicas, sendo que no âmbito do direito internacional, por exemplo, as Diretrizes da ONU para a Defesa do Consumidor, de 1985, recebeu em 1999 como acréscimo o direito ao consumo sustentável. (DEFOSSEZ, 2017).

Neste novo ethos, em que as reduções de emissões de gases de efeito estufa e a contenção da pegada ambiental da humanidade é inevitável, caso desejemos que nossas futuras gerações tenham alguma chance de sobreviver, as noções de redução, reuso e reciclagem se tornaram o carro chefe da 
massificação da publicidade ecológica e se disseminou pela sociedade, produzindo como efeito uma redução consciente, generalizada e sistemática do consumo, que se chama consumerismo.

Não se trata de um modismo, ou de um fenômeno ecológico sazonal, a redução de consumo de recursos ambientais finitos é urgente, progressiva e irreversível, uma vez que está consolidada em mais de 4 décadas de estudos sistemáticos dos mais eminentes cientistas da Terra, apoiados e registrados pelo IPCC (Intergovernmental Panel on Climate Change), órgão independente, mantido, desenvolvido e autorizado pela Organização das Nações Unidas e seus 195 signatários.

Em face às ameaças de um evento de extinção, à publicidade e à ideologia que o fenômeno criou na sociedade contemporânea, é de se esperar que novos hábitos de consumo sejam criados e disseminados.

Os três pilares desses novos hábitos (redução, reutilização e reciclagem) produzem a conscientização do consumo, ou seja, a noção amplamente disseminada de que é preciso perguntar, antes de comprar algo, se realmente aquele produto ou serviço é necessário.

Em tal reflexão materializa-se a redução progressiva e sistemática do consumo que pode, em algum momento entrar em conflito com o preceito defendido por Antunes (2009, p. 179), para quem a própria Carta Cidadã orienta que a justiça e a segurança devam permear o desenvolvimento econômicosocial.

Certamente há que notar-se a contradição premente entre desenvolvimento econômico e redução de consumo. Nesta perspectiva, estando correta a interpretação de Antunes (2009), a própria CF precisaria ter sua orientação mudada, uma vez que é justo e sabido que as leis são feitas para a humanidade, não a humanidade para as leis.

Evitando o mal de Ícaro, não se deve voar tão alto. A análise desta pesquisa se limita a dois diplomas legais muito mais modestos, o Código de Defesa do Consumidor e à Lei de Crimes Contra a Ordem Tributária, em seus aspectos que podem ser associados à redução generalizada do consumo. 


\section{CÓDIGO DE DEFESA DO CONSUMIDOR E CONSUMERISMO}

O Código de Defesa do Consumidor (CDC) foi instituído em 1990 como ferramenta de proteção da ordem pública, do consumidor e do interesse social por meio do desenvolvimento da Política Nacional das Relações de Consumo. A referida norma determina como consumidor toda pessoa física, jurídica ou coletividade que adquira ou utilize algum produto ou serviço como destinatário final. Além desta, o Art. 3ำ do CDC também apresentada as definições de fornecedor, produtos e serviços.

Conforme Defossez (2017) o direito do consumidor no Brasil é determinado como um valor constitucional, fato que a autora considera um erro, ao analisar a prevalência do mesmo sobre as regulamentações específicas, como no caso da Agência Nacional de Aviação, ou da Convenção de Montreal, cujas determinações têm sido preteridas pelo Supremo Tribunal Federal (STF) em favor da interpretação do CDC nas demandas do setor de aviação. Para a autora este alto nível jurídico dado ao direito do consumidor não garante a preservação de seus interesses e ainda lança pesados fardos sobre os fornecedores devido, à criação de incertezas jurídicas.

O Art. 4ํ do CDC, sobre a Política Nacional das Relações de Consumo, sustenta como metas, entre outras, proteger os interesses do consumidor, melhorar a sua qualidade de vida e a buscar a harmonia e transparência quanto às relações de troca. Nessa perspectiva a oposição entre crescimento econômico e consumerismo produz uma contradição explícita.

Em outros termos, ou a lei defende a qualidade de vida do consumidor, propiciada pela redução da pegada ambiental, ou apoia os interesses econômicos e a harmonia das relações de consumo, materializados no crescimento da economia, que é um subproduto do aumento de consumo.

A contradição exposta deriva do fato de que o texto legal foi produzido em um ethos diverso do atual e por relações de poder anteriores à disseminação do consumerismo, encontroando-se em processo de obsolescência, que pode gerar 
conflitos de interesse quanto à defesa e expressão de objetivos políticos potencialmente contraditórios.

Em um cenário provável de generalização do consumerismo algo que não se deve esperar é a harmonia nas relações de consumo. O consumo consciente deprime os preços, tornando certas escalas de produção proibitivas e ampliando a concorrência, que se desencadeia em falências, redução do nível de emprego e renda, ou seja, um ciclo vicioso depressivo no qual certos agentes econômicos, especialmente os fornecedores, tornam-se vítimas potenciais das novas relações de consumo, vítimas estas que não estão sob o amparo dos objetivos e princípios da Política Nacional das Relações de Consumo, a qual reconhece apenas a vulnerabilidade do consumidor e não das demais partes envolvidas nas relações de troca.

Tal perspectiva se torna ainda problemática em relação à legislação internacional, no que diz respeito à reciprocidade, uma vez que outros parceiros comerciais importantes do Brasil, como os Estados Unidos e a União Europeia não têm a mesma estrutura constitucional de proteção ao consumidor, conforme Defossez (2017). Este fenômeno fragiliza a competitividade das empresas nacionais e desestimula o investimento estrangeiro em diversos setores.

O artigo quarto do CDC adota como fundamento compatibilizar o desenvolvimento tecnológico e econômico com os interesses do consumidores, a fim de favorecer os fundamentos em que se assentam a ordem econômica, sem prescindir da boa-fé e da manutenção de relações equilibradas em relação ao consumo. (CUNHA, 2005).

Em visita ao disposto no artigo 170 da Carta Cidadã, observa-se que a ordem econômica se fundamenta sobre o trabalho humano, a livre iniciativa e tem como objetivos assegurar a existência digna de todos em observância à justiça social.

São princípios assegurados constitucionalmente para a manutenção da ordem econômica, dentre outros, a livre concorrência, a defesa do consumidor e, curiosamente vetado e alterado pela Emenda 42 a defesa do meio ambiente, que voltou a vigorar em 2003, com adendos. 
Os vetos ao Art. 170 da CF não alteraram os demais princípios referentes ao emprego, propriedade, livre iniciativa ${ }^{1}$, etc..., com manutenção do inciso IX, que visa proteger empreendimentos nacionais de pequeno porte. Quanto às demais empresas, médias e grandes, não foi encontrado nesses diplomas legais proteções específicas em relação ao consumerismo.

Não obstante, são estas pessoas jurídicas as mais ameaçadas pelo fenômeno, uma vez que seus planos de ação e estratégias de investimento, devido à escala em que trabalham, são concebidos em uma perspectiva de crescimento do consumo a longo prazo.

De outro ponto de vista, dentre os princípios da Política Nacional das Relações de Consumo do CDC, consta o compromisso de prestação de informações aos consumidores quanto aos seus direitos, o incentivo aos fornecedores para gestão do controle de qualidade, além da criação e manutenção de ferramentas para solucionar conflitos de consumo, repreender a deslealdade na concorrência e a criação de símbolos, produtos, marcas e nomes comerciais nocivos aos consumidores.

É nesse aspecto legal, instituído pelo inciso VI do Art. 4º do CDC, que pode aventar-se a disposição de conflito ao provar-se o incentivo, por parte dos fornecedores, ao consumo irrefletido, ou de substâncias potencialmente danosas ao consumidor, ou ao meio em que vive, uma vez que um ambiente degradado efetivamente provoca prejuízos de diversas naturezas, gerando o direito à reparação, sustentado pelo Art. 5ำ da CF, pelo qual as empresas podem ser juridicamente responsabilizadas.

Neste aspecto, artigo sexto do CDC é ainda mais claro, em seu inciso primeiro, prescrevendo como direito básico do consumidor ter protegida a segurança, a saúde e a vida dos riscos oferecidos por praticas inadequadas quanto ao fornecimento de serviços ou produtos "nocivos".

Além disto, o inciso IV implica na proteção do consumidor contra publicidade enganosa e abusiva, de modo que permite a interpretação de que

1 Abreu e Dalton Robert (2018) observam que, no caso do setor de planos de saúde, o direito à livre iniciativa foi suplantado pelo direito fundametal à boa regulação, a partir de legislação específica. 
os danos ao meio ambiente provocados pela maioria dos produtos industrializados sejam entendidos como efeito de má-fé nas relações comerciais, já que seus conhecidos processos deletérios não são claramente destacados nas campanhas publicitárias, uma vez que reverteriam o efeito do marketing.

Reza o CDC, em seu artigo sexto, inciso sexto, que é direito do consumidor a efetiva reparação dos danos causados pelas relações de consumo, sejam patrimoniais, morais, individuais, coletivos ou difusos. O Art. 81 define direitos difusos como aqueles indivisíveis por natureza, transindividuais e dos quais pessoas indeterminadas são de fato titulares.

Essas cláusulas legais abrangem os danos ambientais causados por fornecedores, cujo ônus da prova têm reversão garantida pelo inciso VIII do Art. 6 em caso de hipossuficiência de provas, assim como deve-se observar a solidariedade da reparação em casos envolvendo mais de um autor, conforme o parágrafo único do Art. 7.

Em favor dos fornecedores o Art. 8, na Seção I do CDC, que trata da proteção à saúde, atenua a norma, indicando que os produtos não podem fornecer riscos à segurança e saúde dos consumidores, excetuando-se aqueles que são considerados oriundos da natureza dos produtos, caso em que o fornecedores ficam obrigados a prestar as informações adequadas sobre os riscos.

O aspecto supracitado da norma jurídica permite ao magistrado ponderar em que medida o risco causado por um produto disponibilizado no mercado pode ser considerado normal, não obstante a obrigação do fornecedor de publicar a existência de tais riscos, sendo que aqueles relativos à contaminação, nocividade ou perigo à saúde, ou segurança, devem ser informados de maneira ostensiva e adequada, conforme ordenam os Art. 8 §2 e Art. 9 do CDC.

A ignorância da periculosidade de um produto não diminui a obrigação do fornecedor de informar ostensivamente sobre a mesma, assim que tiver conhecimento dos fatos, tão pouco mitiga a sua responsabilidade sobre os efeitos. Outrossim, independentemente da culpa, os fornecedores respondem pela reparação dos danos causados aos consumidores por defeitos em geral, 
assim como por falhas de comunicação acerca dos riscos apresentados pelos produtos, conforme o Art. 12 do CDC.

A norma, em seu Art. $37 \S 1$ determina como enganosa toda publicidade que, mesmo por omissão, possibilite levar o consumidor ao engano sobre as características, natureza, quantidade preço, origem e demais propriedades do serviço ou produto. Nestes termos, não é absurdo sustentar que o incentivo a hábitos de consumo considerados como danosos ao ambiente possam ser interpretados como efeito de campanhas publicitárias que não informem ostensivamente os riscos ambientais provocados pelos produtos ofertados, ensejando ações reparatórias das mais diversas modalidades.

O parágrafo segundo do Art. 37 é ainda mais específico quanto ao incentivo de fornecedores ao consumo irresponsável ou de produtos potencialmente danosos, classificando como abusiva toda publicidade que produzem ou incentivam o consumidor a desrespeitar os valores ambientais, induzindo-o a comportamentos danosos à segurança ou à saúde.

Por fim, o Art. 51, XIV do CDC dita que são nulas de pleno direito as cláusulas contratuais que violem ou viabilizem a infração da legislação ambiental. Não obstante, conforme o Art. 61 e 63 do mesmo diploma legal, constitui crime contra as relações de consumo a omissão de informações ostensivas acerca do perigo ou nocividade dos produtos em suas embalagens, invólucros ou publicidade. Da mesma forma é ato criminoso a publicidade enganosa e a omissão às autoridades de informações técnicas relevantes quanto ao perigo potencial de produtos e serviços.

As penas prescritas variam de detenção de seis meses a três anos e multa. As mesmas podem ser agravadas se os fatos ocorrerem em períodos de calamidade, grave crise econômica, envolvam alimentos ou produtos essenciais, dentre outros. 


\section{OS CRIMES CONTRA A ORDEM TRIBUTÁRIA E CONSUMERISMO}

A Lei № 8.137, de 1990 define os crimes contra as relações de consumo e a ordem tributária. Por tratar-se de legislação específica sobre o tema, propõese uma análise dos pontos ligados direta ou indiretamente às causas e efeitos do consumerismo.

O estatuto supracitado, em seu artigo sétimo, inciso sete, considera criminosa a indução do usuário ou consumidor ao erro, em caso de indicação ou propagação de informação enganosa ou falsa sobre o serviço ou produto através de publicidade ou outro meio de comunicação. Essa é a caracterização de crime "contra as relações de consumo". (Lei No 8.137/90). Considerando-se a criminalização da indução ao erro, entende-se que o estímulo, por parte dos fornecedores, a hábitos de consumo ou produtos com potencial de danos à saúde, ou ao meio ambiente, se enquadra, também, na mesma tipificação criminosa.

Vieira (2010, p. 641) caracteriza a sociedade de consumo por sua vulnerabilidade em relação à necessidade de defesa do consumidor por meio das normas jurídicas orientadas para tal função, as quais são condicionadas pelos princípios e valores constitucionais, em reconhecimento simultâneo da ausência de hierarquia entre os fundamentos da ordem econômica e os direitos fundamentais, em sua vinculação horizontal quanto à eficácia.

Em uma perspectiva jurídica horizontalizada da relação entre a ordem econômica e os direitos fundamentais, protegidos pelo Art. 5 da CF, as disputas que podem surgir acerca dos efeitos da redução do consumo tendem a produzir grandes embaraços decisórios, uma vez estabelecida a contradição entre desenvolvimento e consumerismo. 


\section{CONCLUSÃO}

A leitura e interpretação do Código de Defesa do Consumidor a partir da perspectiva de um avanço agressivo do consumerismo na sociedade brasileira mostrou que o direito do consumidor no Brasil é determinado como um valor constitucional, assentado na quinta cláusula pétrea da Carta Cidadã.

Por outro lado, a mesma base fundamental do ordenamento jurídico brasileiro defende a saúde, a habitação, propriedade, a liberdade e todas as demais garantias fundamentais atinentes aos direitos humanos, de modo que enquanto as relações de consumo mantiverem-se em harmonia com as condições mínimas de dignidade humana não há contradição na lei, pois que estes fundamentos permanecem em estado de horizontalidade jurídica.

Entretanto, uma abrupta, sistemática e persistente redução no consumo pode desarmonizar tais fundamentos, uma vez que promove a depressão das condições mínimas de estabilidade econômica e, portanto, interfere tanto na capacidade do Estado de fomentar os direitos essenciais, quanto na do mercado de manter o equilíbrio de trocas. Nestas circunstâncias far-se-á necessário hierarquizar as normas constitucionais, privilegiando ou as relações de consumo, ou os direitos humanos.

A emergência do conflito jurídico entre o Art. 5 da CF e o Código de Defesa do Consumidor, derivado das condições ambientais em curso, é uma oportunidade de repensar o ordenamento jurídico brasileiro como um todo e de estabelecer novos status normativos tanto para as relações de consumo, quanto para a defesa dos direitos humanos. 


\section{REFERÊNCIAS}

ANTUNES, Júlia Caiuby de Azevedo. A previsibilidade nas condenações por danos morais: uma reflexão a partir das decisões do STJ sobre relações de consumo bancárias. Rev. direito GV, São Paulo, v. 5, n. 1, p. 169-184, June 2009 Disponível

em:

<http://www.scielo.br/scielo.php?script=sci_arttext\&pid=S1808-

24322009000100009\&Ing=en\&nrm=iso>. Acesso em 17 out. 2019. http://dx.doi.org/10.1590/S1808-24322009000100009.

ABREU, Célia Barbosa e Tibúrcio, DALTON ROBERT Oferta obrigatória de planos de saúde individuais e familiares: livre iniciativa e direito fundamental à boa regulação. Rev. Investig. Const., Ago 2018, vol.5, no.2, p.209-233. ISSN 2359-5639

BRASIL. Constituição da República Federativa do Brasil de 1988. Brasília: Presidência da República, [1988]. Disponível em: http://www.planalto.gov.br/ccivil_03/Constituicao/Constituicao.htm. Acesso em: 17 nov. 2019.

CUNHA, Patrícia G. M. Aplicação de acordos Internacionais à luz do direito do consumidor. 2005. 64 f. Monografia (Bacharelado) - Curso de Direito, Departamento de Direito, Pontifícia Universidade Católica do Rio de Janeiro, Rio de Janeiro, 2005. Disponível em: <https://www.maxwell.vrac.pucrio.br/10134/10134.PDF>. Acesso em: 17 nov. 2019.

DEFOSSEZ, Delphine aurelie Laurence. Consumer law in Constitution: a big mistake? The specific case of aviation in Brazil. Rev. Investig. Const., Dec 2017, vol.4, no.3, p.61-83. ISSN 2359-5639.

VIEIRA, Nelise Dias. Constitutional interpretation of the development risks in the brazilian consumer's law: national and international legal views. Rev. direito GV, São Paulo , v. 6, n. 2, p. 641-644, Dec. 2010 . Disponível em: <http://www.scielo.br/scielo.php?script=sci_arttext\&pid=S1808-

24322010000200014\&Ing=en\&nrm=iso>. Acesso em 17 out. 2019. http://dx.doi.org/10.1590/S1808-24322010000200014. 